\title{
Study on Synthesis of PAEKs Containing Triazole Units through Click Reaction and Their Properties
}

\author{
Lian-jun Wang, ${ }^{\dagger, * * *}$ Jie Li, ${ }^{\dagger}$ and Le-yong Wang ${ }^{\dagger}$ \\ ${ }_{\dagger}^{\dagger}$ School of Chemistry and Chemical Engineering, Nanjing University, Nanjing 210093, P. R. China \\ 'School of Chemistry and Chemical Engineering, Hunan Institute of Engineering, Hunan 411104, P. R. China \\ *E-mail: wangljchem@gmail.com \\ Received June 9, 2011, Accepted July 20, 2011
}

\begin{abstract}
A series of novel linear aromatic ether ketone polymers containing triazole units were synthesized by click chemistry and their structures and properties were characterized by FT-IR, ${ }^{1} \mathrm{H}$ NMR, GPC, TGA, DSC and WAXD. The results showed that these polymers exhibited relatively small molecular weights distributions, good thermal stability and solvent-repelling which could have potential applications as engineering thermoplastic.
\end{abstract}

Key Words : Click chemistry, Poly(arylene ether ketone), Triazoles, Engineering thermoplastic

\section{Introduction}

Poly(arylene ether ketone)s (PAEKs) are well accepted as a class of high performance engineering thermoplastics known for their excellent combination of thermal and chemical stability and mechanical properties such as creep resistance, high strength and durability and superior electrical insulating ability, due to containing rigid and thermally stable arylene and flexible and heat resistant oxygen ether or sulfide bonds. ${ }^{1-4}$ These advanced materials have been receiving considerable attention for past decades due to their successful applications in aerospace, automobile, electronics and other high technology fields, ${ }^{5}$ such as high-temperature coating, toughening agents, ultrafiltration membranes and ionic exchange membrane after carrying ionic exchange groups for fuel cell and vanadium redox battery so on.

Due to these advantages, Poly(arylene ether ketone)s are being synthesized to obtain superior qualifications. The most popular synthetic route to poly(arylene ether ketone)s is aromatic nucleophilic substitution of aromatic dihydroxy compounds and activated aromatic dihalo- or dinitro- compounds. However, this polymerization generally needs high temperature $\left(>160^{\circ} \mathrm{C}\right)$ and long reaction time. ${ }^{6}$

Recently, click chemistry, the copper (I)-catalyzed Huisgen's 1,3-diploar cycloadditions of azides and terminal alkynes has attracted much attention. ${ }^{7,8}$ Because of their high selectivity, near-perfect reliability, high yields, and exceptional tolerance towards a wide range of functional groups and reaction conditions, click chemistry have recently attracted increasing attention in organic synthesis, ${ }^{9}$ supermolecular chemistry and material surface modification. ${ }^{10,11}$ In particular, click chemistry is increasingly used in engineering thermoplastic polymer synthesis. ${ }^{12,13}$

In this article, we describe the synthesis and characterization of a novel class of linear aromatic ether keton/ sulfone polymers containing triazole units from the click chemistry of new monomer 4,4'-bis(azidomethyl) diphenyl ketone and bisethynyl compounds.

\section{Experimental Part}

Materials. Acetone, DMSO were dried from $\mathrm{CaH}_{2}$, and distillated before use. Other reagents ( $N, N$-dimethylformamide (DMF), 1-methyl-2-pyrrolidinone (NMP), dimethylacetamide (DMAc), Methanol $(\mathrm{MeOH})$, tetrahydrofuran (THF), toluene ) or materials were used as received.

Measurements. Infrared spectra were obtained on Thermo Electron Corporation Nicolet 380 FT-IR spectrophotometer. ${ }^{1} \mathrm{H}$ NMR (400 MHz) was recorded on a BrukerAM-400 spectrometer with $\mathrm{Me}_{4} \mathrm{Si}\left({ }^{1} \mathrm{H}\right.$ NMR) as internal standard. Relative molecular weights and molecular weight distributions were measured by gel permeation chromatography (GPC) system equipped with a Waters 1515 Isocratic HPLC pump, a Waters 2414 refractive index (RI) detector, a Waters 2487 dual-wavelength $\lambda$ absorbance detector and a set of Waters Styragel columns (HR3, HR4 and HR5, $7.8 \mathrm{~mm} \times$ $300 \mathrm{~mm}$ ). GPC measurements were carried out at $35^{\circ} \mathrm{C}$ using DMSO as eluent at a flow rate of $1.0 \mathrm{~mL} / \mathrm{min}$. The system was calibrated with polystyrene standards. Differential scanning calorimetry (DSC) was conducted on a NetZSch (German) DSC 204 F1 system under nitrogen calibrated with indium and zinc standards. Initial sample weight was set as $1-2 \mathrm{mg}$ for each operation. The specimen was heated from 25 to $280^{\circ} \mathrm{C}$ at a heating rate of $10^{\circ} \mathrm{C} / \mathrm{min}$. Thermogravimetric analysis (TGA) was performed on NetZSch (German) TGA 209 F1 system on powder samples at a heating rate of $10{ }^{\circ} \mathrm{C} / \mathrm{min}$ under nitrogen atmosphere from 25 to $700{ }^{\circ} \mathrm{C}$. Wide-angle X-ray diffraction (WAXD) patterns were obtained at room temperature on a Rigaku D/ Max-2550 powder diffractometer with a scanning speed of $5 \% \mathrm{~min}$, and the patterns were recorded in the $2 \theta$ range of 5 $60^{\circ}$.

Synthesis of 4,4'-bis(azidomethyl) diphenyl Ketone Compound. 
Synthesis of 4,4'-dimethyl Benzophenone: To a $500 \mathrm{~mL}$ three-necked flask equipped with a magnetic stirrer, a dropping funnel, a condenser upper with a $\mathrm{CaCl}_{2}$ drying tube linked to a gas absorber was added anhydrous aluminium chloride ( $75 \mathrm{~g}, 0.55 \mathrm{~mol})$, toluene $(150 \mathrm{~mL})$. Then stirring to mixture uniform, 4-methylbenzoyl chloride ( $77.3 \mathrm{~g}, 0.5 \mathrm{~mol})$ was dropped from the dropping funnel over a period of $1 \mathrm{~h}$ maintaining temperature between -5 to $0{ }^{\circ} \mathrm{C}$, after complete addition of 4-methylbenzoyl chloride, the reaction was further stirred for 5-6 $\mathrm{h}$ at $0-5{ }^{\circ} \mathrm{C}$ to ensure complete consumption of 4-methylbenzoyl chloride (by observing no $\mathrm{HCl}$ gas escape in gas absorber). The reaction mixture was then slowly poured in to a mixture of crushed ice $(2 \mathrm{Kg})$ and conc. $\mathrm{HCl}(900 \mathrm{~mL})$ maintaining temperature between 0 to $10{ }^{\circ} \mathrm{C}$. The products were extracted into ethyl acetate $(1000$ $\mathrm{mL})$. The ethyl acetate layer was separated and washed with water to neutral $\mathrm{pH}$ (6-7). Finally ethyl acetate was concentrated on a rotary evaporator to give 4,4'-dimethyl benzophenone as a solid.

(80.4 g, 52\%): mp 92.7-93.4 ${ }^{\circ} \mathrm{C} .{ }^{1} \mathrm{H}$ NMR $\left(\mathrm{CDCl}_{3}, 400\right.$ $\mathrm{MHz}, \mathrm{ppm}): \delta 7.71(4 \mathrm{H}, \mathrm{d}, J=5.6 \mathrm{~Hz}), 7.28(4 \mathrm{H}, \mathrm{d}, J=8.0$ $\mathrm{Hz}), 2.44(6 \mathrm{H}, \mathrm{s})$. IR $\left(\mathrm{KBr}, \mathrm{cm}^{-1}\right): 3035,2919,2855,1924$, $1650,1605,1558,1446,1406,1314,1279,1177,1148$, 1112, 1041, 929, 825, 750. MS (EI): $m / z ~ 210,195,119,91$, 65. Anal. Calcd for $\mathrm{C}_{15} \mathrm{H}_{14} \mathrm{O}: \mathrm{C}, 85.68 \%$; H, 6.71\%. Found: C, $85.91 \%$; H, 6.74\%.

Synthesis of 4,4'-bis(bromomethyl) diphenyl Ketone: A mixture of 4,4'-dimethyl benzophenone ( $50 \mathrm{~g} 0.24 \mathrm{~mol}), \mathrm{N}$ bromosuccinimide (NBS, $85 \mathrm{~g}, 0.48 \mathrm{~mol}$ ) and dry $\mathrm{CCl}_{4}(400$ $\mathrm{mL}$ ) was stirred and refluxed under the light of two "IR 275 W" lamps until the starting material was completely transformed (ca. 1-3 h). The reaction mixture was cooled to room temperature, succinimide was filtered off and the solvent was removed on a rotary evaporator to give crude product. The crude product was recrystallized from ethanol to afford 4,4'-bis(bromomethyl) diphenyl keton.

(81.9 g, 72\%): mp 126-128 ${ }^{\circ} \mathrm{C} .{ }^{1} \mathrm{H}$ NMR $\left(\mathrm{CDCl}_{3}, 400\right.$ MHz, ppm): $\delta 7.79$ (d, $J=8.4 \mathrm{~Hz}, 4 \mathrm{H}), 7.52(\mathrm{~d}, J=8.4 \mathrm{~Hz}$, $4 \mathrm{H}), 4.54(\mathrm{~s}, 4 \mathrm{H}) . \mathrm{IR}\left(\mathrm{KBr}, \mathrm{cm}^{-1}\right) \vee 3072,2916,2848,1700$, 1646, 1608, 1437, 1412, 1348, 1278, 1175, 930, 851, 610. MS (EI): $m / z$ 367, 289, 287, 180, 118, 104, 90, 89, 63, 39. Anal. Calcd for $\mathrm{C}_{15} \mathrm{H}_{12} \mathrm{Br}_{2} \mathrm{O}: \mathrm{C}, 48.95 \%$; H, 3.29\%. Found: C, $49.13 \%$; H, 3.37\%.

Synthesis of 4,4'-bis(azidomethyl) diphenyl Ketone: To a $500 \mathrm{~mL}$ single necked flask equipped with a reflux condenser and a magnetic stirrer were added 4,4'-bis(bromomethyl) diphenyl ketone $(73.6 \mathrm{~g}, 0.20 \mathrm{~mol})$ and $\mathrm{NaN}_{3}$ $(26 \mathrm{~g}, 0.40 \mathrm{~mol})$ in DMF $(300 \mathrm{~mL})$. The reaction mixture was stirred at $90{ }^{\circ} \mathrm{C}$ for $24 \mathrm{~h}$. After the mixture was cooled to room temperature, the solution was diluted with and extracted with ether $(3 \mathrm{~mL} \times 100 \mathrm{~mL})$. The combined organic layer was washed with saturated brine solution $(100 \mathrm{~mL})$, dried and concentrated in vacuo. The residue was purified by column chromatography on silica gel using petroleum ether/ ethyl acetate (10:1) as eluent to give 4,4'-bis(azidomethyl) diphenyl ketone.

(5.3 g, 90\%): mp 75.9-76.1 ${ }^{\circ} \mathrm{C} .{ }^{1} \mathrm{H}$ NMR $\left(\mathrm{CDCl}_{3}, 400\right.$
MHz, ppm): $\delta 7.82(\mathrm{~d}, J=8.0 \mathrm{~Hz}, 4 \mathrm{H}), 7.45(\mathrm{~d}, J=8.4 \mathrm{~Hz}$, $4 \mathrm{H}), 4.46(\mathrm{~s}, 4 \mathrm{H})$. IR $\left(\mathrm{KBr}, \mathrm{cm}^{-1}\right) \vee 3072,2916,2849,2100$, 1701, 1646, 1608, 1437, 1412, 1348, 1278, 1175, 930, 851. MS (EI): $m / z$ 250, 236, 194, 132, 104, 76, 51. Anal. Calcd for $\mathrm{C}_{15} \mathrm{H}_{12} \mathrm{~N}_{6} \mathrm{O}$ : C, 61.64\%; H, 4.14\%; N, 28.75\%. Found: $\mathrm{C}$, $61.94 \%$; H, 4.24\% N, 27.27\%.

Synthesis of Bisethynyl Compounds 26a-e Containing Arylene Ether Units.

Compouds Ia-e were prepared according to the ref. 7.

Synthesis of Polymer IIa-e: $\mathrm{CuSO}_{4} \cdot 5 \mathrm{H}_{2} \mathrm{O}(7 \mathrm{mg}, 5 \mathrm{~mol} \%)$ and sodium ascorbate $(12 \mathrm{mg}, 10 \mathrm{~mol} \%)$ dissolved in $\mathrm{H}_{2} \mathrm{O}$ $(10 \mathrm{~mL})$ were added dropwise to a solution of bisethynyl compounds ( $0.50 \mathrm{mmol})$ and 4,4'-bis(azidomethyl) diphenyl ketone (146 mg, $0.50 \mathrm{mmol})$ in DMSO (15 mL).The reaction mixture was stirred at $45{ }^{\circ} \mathrm{C}$ overnight. The solvent was decanted to leave a gum residue in the flask. The residue was then stirred in $\mathrm{H}_{2} \mathrm{O}(20 \mathrm{~mL})$ and concentrated ammonia $(5 \mathrm{~mL})$ for another $1 \mathrm{~h}$. The mixture was filtered and the resulting filter cake was washed with $\mathrm{H}_{2} \mathrm{O}(3 \mathrm{~mL} \times 20$ $\mathrm{mL}$ ). The filter cake was then dissolved in DMSO, filtered again and precipitated into a 2:1 solution of water and methanol. The solid was separated and washed repeatedly with aqueous methanol before dried in a vacuum oven. The desired polymers IIa-e were obtained as pale yellow solids, respectively.

IIa: $66 \%$ yield. ${ }^{1} \mathrm{H}$ NMR (DMSO- $\left.d_{6}, 400 \mathrm{MHz}, \mathrm{ppm}\right) \delta$ 8.32 (2H, s), 7.73 (4H, br), 7.48 (4H, br), 6.96 (4H, br), 5.74 (4H, br), 5.08 (4H, br). IR (KBr, cm $\left.{ }^{-1}\right): v 3134,3079,2934$, 2870, 1650, 1608, 1570, 1505, 1460, 1414, 1313, 1278, $1221,1204,1109,1049,1016,928,821,745,710 . \mathrm{Mn}=$ $18543, \mathrm{Mw}=27355, \mathrm{PI}=1.47$.

IIb: $51 \%$ yield. ${ }^{1} \mathrm{H}$ NMR (DMSO- $\left.d_{6}, 400 \mathrm{MHz}, \mathrm{ppm}\right) \delta$ 8.33 (2H, s), 7.72 (4H, br), 7.45 (4H, br), 7.17 (1H, br), 6.71 (1H, br), $6.62(2 \mathrm{H}, \mathrm{br}), 5.73$ (4H, br), $5.12(4 \mathrm{H}, \mathrm{br})$. IR (KBr, $\left.\mathrm{cm}^{-1}\right): v 3138,3062,2939,2872,1656,1607,1586,1490$, $1460,1415,1313,1278,1223,1178,1149,1104,1049$, $1019,928,807,762,738 . \mathrm{Mn}=17851, \mathrm{Mw}=27213, \mathrm{PI}=$ 1.52 .

IIc: $70 \%$ yield. ${ }^{1} \mathrm{H}$ NMR (DMSO- $\left.d_{6}, 400 \mathrm{MHz}, \mathrm{ppm}\right) \delta$ 8.32 (2H, s), 7.72 (4H, br), 7.44 (4H, br), 7.10 (4H, br), 6.70 (4H, br), 5.70 (4H, br), 5.11 (4H, br), $1.56(6 \mathrm{H}, \mathrm{br})$. IR (KBr, $\left.\mathrm{cm}^{-1}\right): v 3135,3075,2965,2934,2872,1649,1605,1570$, 1508, 1460, 1413, 1312, 1229, 1204, 1109, 1050, 1012, 928, $821,742,709 . \mathrm{Mn}=22165, \mathrm{Mw}=24232, \mathrm{PI}=1.09$.

IId: $65 \%$ yield. ${ }^{1} \mathrm{H}$ NMR (DMSO- $\left.d_{6}, 400 \mathrm{MHz}, \mathrm{ppm}\right) \delta$ 8.36 (2H, s), 7.75 (4H, br), 7.68 (4H, br), 7.48 (4H, br), 7.17 (4H, br), $5.72(4 \mathrm{H}, \mathrm{br}), 5.23(4 \mathrm{H}, \mathrm{br}) . \mathrm{IR}\left(\mathrm{KBr}, \mathrm{cm}^{-1}\right): \mathrm{v}$ 3136, 3063, 2938, 2872, 1707, 1648, 1598, 1569, 1505, $1460,1415,1306,1279,1246,1204,1165,1148,1114$, $1048,1029,998,946,925,848,766,727 . \mathrm{Mn}=19190, \mathrm{Mw}$ $=26988, \mathrm{PI}=1.41$.

IIe: $62 \%$ yield. ${ }^{1} \mathrm{H}$ NMR (DMSO- $\left.d_{6}, 400 \mathrm{MHz}, \mathrm{ppm}\right) \delta$ 8.35 (2H, s), 7.85 (4H, br), 7.76 (4H, br), 7.57 (4H, br), 7.22 (4H, br), $5.72(2 \mathrm{H}, \mathrm{br}), 5.23(4 \mathrm{H}, \mathrm{br}) . \mathrm{IR}\left(\mathrm{KBr}, \mathrm{cm}^{-1}\right): v$ 3133, 3076, 2931, 2872, 1650, 1598, 1569, 1498, 1460, 1415, 1310, 1285, 1255, 1164, 1148, 1110, 1047, 1028, 947, $828,727 . \mathrm{Mn}=15580, \mathrm{Mw}=21806, \mathrm{PI}=1.40$. 


\section{Results and Discussion}

Synthesis and Characterization of Polymers. The polymers containing triazole unites IIa-e were obtained from the click reactions of monomers 4,4'-bis(azidomethyl) diphenyl ketone and 6a-f respectively (Scheme 1 and 2). Click reactions were carried out in a 3:2 solvent ratio of DMSO to $\mathrm{H}_{2} \mathrm{O}$ using $5 \mathrm{~mol} \% \mathrm{CuSO}_{4} \cdot 5 \mathrm{H}_{2} \mathrm{O}$ with $10 \mathrm{~mol} \%$ sodium ascorbate as the in situ reducing agent to generate the active $\mathrm{Cu}(\mathrm{I})$ species. $^{8}$ The reaction temperature played key role in the formation of the polymers. It was found that the polymers with reasonable molecular weight were obtained when the click reactions were carried out at $45^{\circ} \mathrm{C}$.

\section{Properties of Polymers.}

Solubility of Polymers: The solubility of polymers IIa-e in common organic solvent was determined quantitatively by dissolving $5.0 \mathrm{mg}$ of solid polymers in $1.0 \mathrm{~mL}$ of solvents (Table 1). It can be seen that solubiltiy of these polymers is poor in solvents listed in Table 1 at room temperature. When

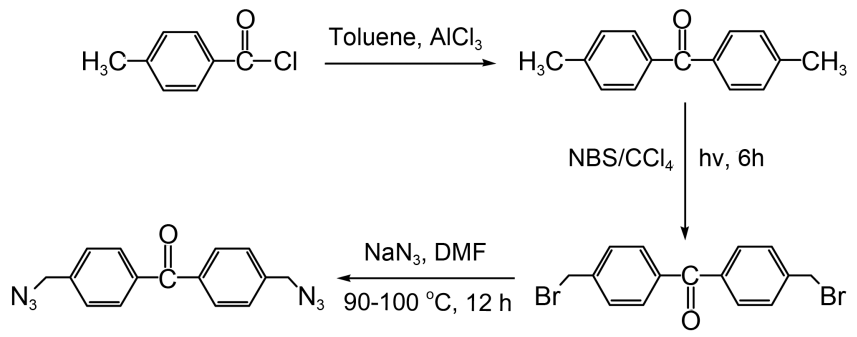

Scheme 1. Synthesis of 4,4'-bis(azidomethyl) diphenyl ketone compound. heating, these polymers all show good solubility in highly polar solvents such as DMF, NMP, DMAc and DMSO, while they can not dissolve in $\mathrm{MeOH}$, THF, Acetone, Toluene. All these polymers possess film forming ability. The polymer solutions ( $8 \%$ ) in polar solvents with $\mathrm{LiCl}$ were processed into thin films by casting onto glass plates. The free-standing films having a thickness in the range of tens of micrometers were flexible, tough, and maintained their integrity after repeated bendings.

Molecular Weights and their Distributions of Polymers: The corresponding data of GPC ananlysis in DMF for polymers IIa-e were listed in Table 2. The data show that the polymerization between 4,4'-bis(azidomethyl) diphenyl ketone and bisethynyl compounds via click chemistry produced polymers IIa-e with fairly good molecular weigths and the distributions. The number average molecular weights of them are around 20000 and the distributions range from 1.4 to 1.5 with the exception of polymer IIc which distribution is narrower (1.09). The reason for the difference is

Table 2. Molecular weights and their distributions of polymers IIae using GPC

\begin{tabular}{cccc}
\hline Polymers & $\mathrm{Mn}^{a}$ & $\mathrm{Mw}^{a}$ & $(\mathrm{Mw} / \mathrm{Mn})^{a}$ \\
\hline IIa & 18543 & 27355 & 1.47 \\
IIb & 17851 & 27213 & 1.52 \\
IIc & 22165 & 24232 & 1.09 \\
IId & 19190 & 26988 & 1.41 \\
IIe & 15580 & 21806 & 1.40 \\
\hline
\end{tabular}

${ }^{a} \mathrm{PC}$ in DMF $v$ s. polystyrene at $35^{\circ} \mathrm{C}$.

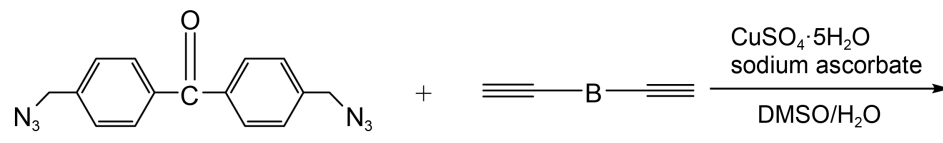

la-e<smiles>CC(C)(C)Bc1cn(Cc2ccc(C(=O)c3ccc(Cn4cc(C(C)(C)C)nn4)cc3)cc2)nn1</smiles>

Ila-e
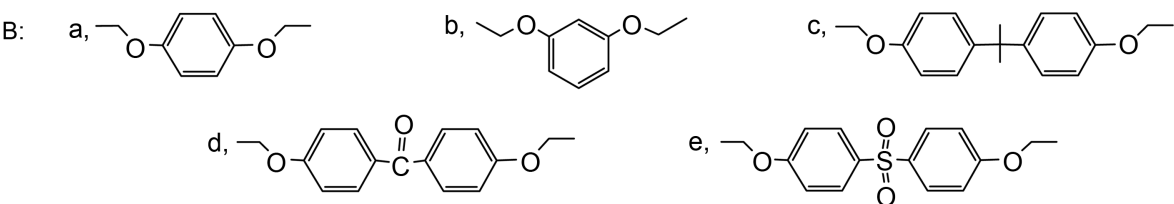

e,

Scheme 2. Synthesis of polymer IIa-e.

Table 1. Solubility of polymers

\begin{tabular}{|c|c|c|c|c|c|c|c|c|}
\hline Polymers & DMF & NMP & DMAc & DMSO & $\mathrm{MeOH}$ & THF & Acetone & Toluene \\
\hline IIa & +- & +- & +- & +- & - & - & - & - \\
\hline IIb & +- & +- & +- & +- & - & - & - & - \\
\hline IId & +- & +- & +- & +- & - & - & - & - \\
\hline IIe & +- & +- & +- & +- & - & - & - & - \\
\hline
\end{tabular}

Note: (+) Soluble; (+-) Soluble when heating; (-) insoluble; (sw) swell. 


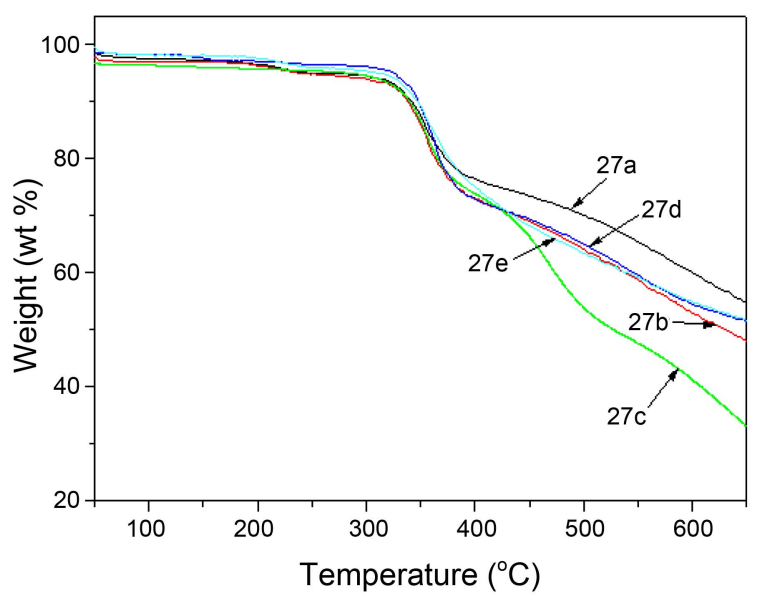

Figure 1. TG curves of polymers IIa-e.

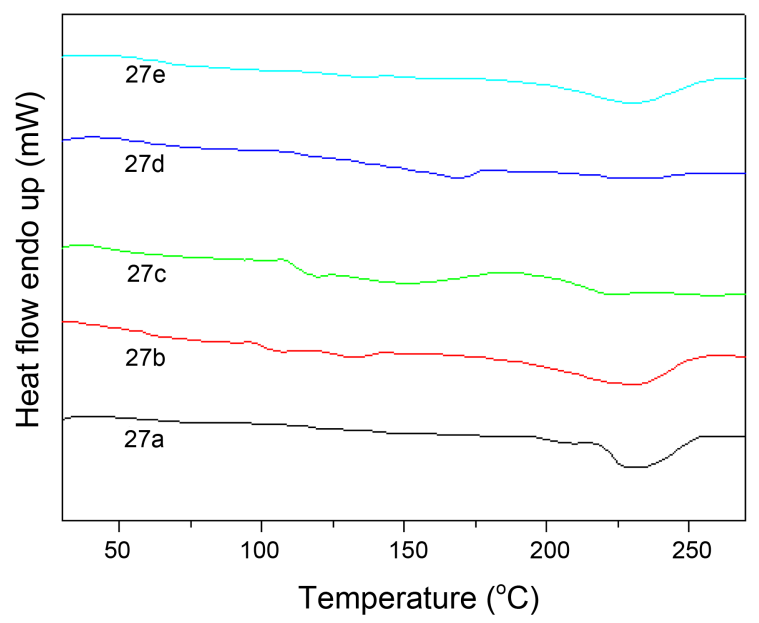

Figure 2. DSC curves of polymers IIa-e.

that IIa, IIb, IId and IIe contain more small molecular polymers with azido than IIc. All polydispersites of polymers are less than 2 which indicated that the click chemistry is a efficient way for polymerization of block polymers.

Thermal Properties of Polymers: Thermal stability of the polymers IIa-e was determinated by means of thermogravimetric analysis (TGA) (Fig. 1) and differential scanning calorimetry (Fig. 2).The resulting data are listed in Table 3. The polymers IIa-e started to decompose at about $330{ }^{\circ} \mathrm{C}$ which probably attribute to breakage of aromatic ether in molecular chain. There were the second stage of weight loss at $363-377^{\circ} \mathrm{C}$. It was seen from Figure 1 that rate of weight loss of IIa was lager than the other polymers. The reason is that the former might be caused by the decomposition of isopropyl group, the latter by decomposition of methylene group. The values of $\mathrm{T}_{\mathrm{g}}$ were determinated from the DSC curves and listed in Table 3. $\mathrm{T}_{\mathrm{g}}$ values of polymers IIa-e were found to be in the increasing order of IIb $<$ IIa $<$ IIC $\approx$ IId $<$ IIe. Tg value of IIe is the highest due to the rigid sulfone groups in the polymer backbone which hinder molecular rotatoin while that of IIb was the lowest owing to the meta-phenylene group which increase flexiblilty of molecular chain. The curves of DSC (Fig. 2) also show that
Table 3. Data of DSC and TGA of polymer IIa-e

\begin{tabular}{ccccc}
\hline Polymers & $\mathrm{T}_{\mathrm{g}}\left({ }^{\circ} \mathrm{C}\right)^{b}$ & $\mathrm{~T}_{\mathrm{d}}\left({ }^{\circ} \mathrm{C}\right)^{b}$ & $\mathrm{~T}_{\mathrm{s}}\left({ }^{\circ} \mathrm{C}\right)^{b}$ & $\mathrm{R}_{\mathrm{w}}(\%)^{c}$ \\
\hline IIa & 104 & 330 & 374 & 55.6 \\
IIb & 96 & 326 & 363 & 47.8 \\
IIc & 110 & 325 & 365 & 33.2 \\
IId & 112 & 332 & 368 & 51.3 \\
IIe & 142 & 334 & 377 & 51.3 \\
\hline
\end{tabular}

${ }^{b}$ Measured at $10{ }^{\circ} \mathrm{C} / \mathrm{min}$ in $\mathrm{N}_{2} ; \mathrm{T}_{\mathrm{d}}$ : onset decompositon temperature; $\mathrm{T}_{\mathrm{s}}$ : $20 \%$ weight loss at the second stage. ${ }^{c}$ Residual weight retention at 650 ${ }^{\circ} \mathrm{C}$.

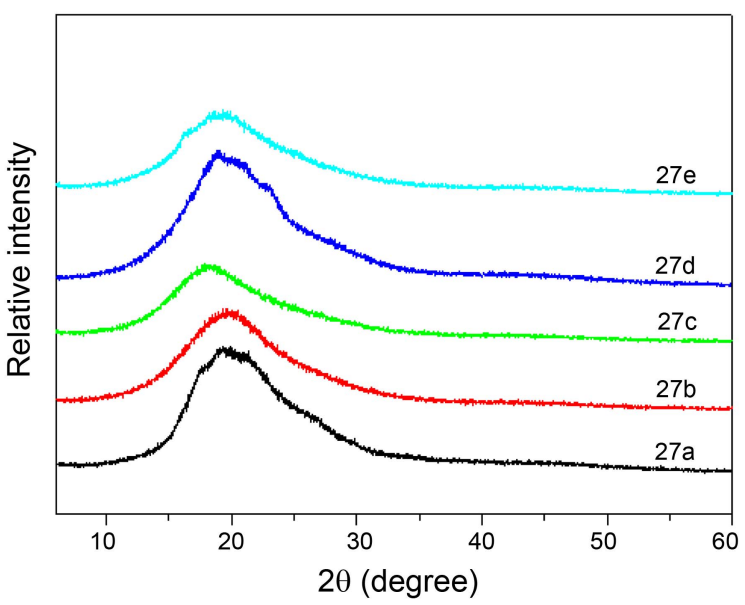

Figure 3. X-ray diffractogram curves of polymer IIa-e.

that all polymers are amorphous, which are required to be confirmed by X-ray of diffraction studies of these polymers.

X-ray Diffraction Studies of Polymer IIa-e: The X-ray diffractogram curves of polymer IIa-e were shown in Figure 3. X-ray diffractograms of all polymers exhibit broad halo at about $2 \theta \approx 15-25^{\circ}$ in the wide angle region indicating that the polymers IIa-e are amorphous in nature which is corresponding to the DSC analysis.

\section{Conclusions}

A novel monoer 4,4'-bis(azidomethyl) diphenyl ketone was prepared .The click chemistry of 4,4'-bis(azidomethyl) diphenyl ketone and bisethynyl compounds Ia-e provided a novel class of linear aromatic ketone polymers containing triazole unites. The resulting polymers mostly are amorphous and have good solubility in most strong polar solvents and thermal stability.

\section{References}

1. Kolb, H. C.; Finn, M. G.; Sharpless, K. B. Angew. Chem. Int. Ed. 2001, 40, 2004.

2. Binder, W. H.; Sachsenhofer, R. Macromol. Rapid Comm. 2007, $28,15$.

3. Gardner, K. H.; Hsiao, B. S.; Faron, K. L. Polymer 1994, 35, 2290.

4. Ji, X. L.; Yu, D. H.; Zhang, W. J.; Wu, Z. W. Polymer 1997, 38, 3501.

5. Hergenrother, P. M. Polymers 2003, 15, 3. 
6. Viswanathan, R.; Johnson, B. C.; McGrath, J. E. Polymer 1984, $25,1827$.

7. Hartmuth, C. K.; Finn, M. G.; Sharpless, K. B. Angew. Chem. Int. Ed. 2001, 40, 2004.

8. Binder, W. H.; Sachsenhofer, R.; Straif, C. J.; Zirbs, R. J. Mater. Chem. 2007, 17, 2125.

9. Wang, Z. X.; Qin, H. L. Chem. Commun. 2003, 2450.

10. Badjiæ J, D.; Balzani, V.; Credi, A.; Lowe, J. N.; Silvi, S.;
Stoddart, J. F. Chem. Eur. J. 2004, 10, 1926.

11. Diaz, D. D.; Punna, S.; Holzer, P.; Mcpherson, A. K.; Sharpless, K. B.; Fokin, V. V.; Finn, M. G. J. Polym. Sci.: Part A: Polym. Chem. 2004, 42, 4392.

12. Zhu, Y.; Huang, Y.; Meng, W.-D.; Li, H.; Qing, F.-L. Polymer 2006, 47, 6272 .

13. Yao, R.-X.; Kong, L.; Yin, Z.-S.; Qing, F.-L. J. Fluorine Chem. 2008, 129, 1003. 